\title{
Article \\ The Structure and Property of Two Different Metal-Organic Frameworks Based on N/O-Donor Mixed Ligands
}

\author{
Zhiqiang Lu ${ }^{1,2}$, , Yanzhi Li ${ }^{1,2}$, Yi Ru ${ }^{1}$, Shujian Yang ${ }^{1}$, Chu Hao ${ }^{1}$, Mengke Zuo ${ }^{1}$, Rongkai Jiao ${ }^{1}$ and Hui Yao ${ }^{2}$ \\ 1 College of Chemistry and Chemical Engineering and Henan Key Laboratory of Function-Oriented Porous \\ Materials, Luoyang Normal University, Luoyang 471934, China; kf18317841228@163.com (Y.L.); \\ ruyi1232@163.com (Y.R.); haoh8526@gmail.com (S.Y.); h2424453591@163.com (C.H.); zmkcat@163.com (M.Z.); \\ jrk251854@163.com (R.J.) \\ 2 Hubei Key Laboratory of Natural Products Research and Development, Key Laboratory of Functional \\ Yeast (China National Light Industry), College of Biological and Pharmaceutical Sciences, China Three \\ Gorges University, Yichang 443002, China; yaohui@ctgu.edu.cn \\ * Correspondence: zqlu2000@lynu.edu.cn; Tel.: +86-15036778326
}

Citation: Lu, Z.; Li, Y.; Ru, Y.; Yang, S.; Hao, C.; Zuo, M.; Jiao, R.; Yao, H. The Structure and Property of Two Different Metal-Organic Frameworks Based on N/O-Donor Mixed Ligands. Crystals 2021, 11, 1129. https:// doi.org/10.3390/cryst11091129

Academic Editors: Paul R. Raithby and Vladimir Fedin

Received: 11 August 2021

Accepted: 12 September 2021

Published: 17 September 2021

Publisher's Note: MDPI stays neutral with regard to jurisdictional claims in published maps and institutional affiliations.

Copyright: (c) 2021 by the authors. Licensee MDPI, Basel, Switzerland. This article is an open access article distributed under the terms and conditions of the Creative Commons Attribution (CC BY) license (https:// creativecommons.org/licenses/by/ $4.0 /)$.
Abstract: Two different metal-organic frameworks (MOFs) $\left[\mathrm{Cd}_{2}(\mathrm{AZN})(\mathrm{HAZN})(\mathrm{btc})(\mathrm{Hbtc}) \cdot 4 \mathrm{H}_{2} \mathrm{O}\right] \cdot 2 \mathrm{H}_{2} \mathrm{O}$ (1), and $\left[\mathrm{Zn}_{3}(\mathrm{AZN})_{2}(\mathrm{btc})_{2} \cdot 4 \mathrm{H}_{2} \mathrm{O}\right]$ (2) were synthesized by the reactions of different metal salts with mixed ligands of 1-(4-(1H-imidazol-5-yl)phenyl)-1H-1,2,4-triazole (AZN) and trimesic acid $\left(\mathrm{H}_{3}\right.$ btc). The different metal centers in the reaction condition have important impact on the resulting structures of MOFs 1 and 2. Compound $\mathbf{1}$ is a one-dimensional (1D) chain structure, while $\mathbf{2}$ features a threedimensional (3D) framework with 3-fold interpenetration topology of Point (Schläfli) symbol of $\left(6 \cdot 8^{2}\right)_{4}\left(6^{2} \cdot 8^{2} \cdot 10^{2}\right)$. Furthermore, the luminescent properties have been studied for MOFs 1 and 2.

Keywords: coordination polymers; characterization; luminescent property

\section{Introduction}

Metal-organic frameworks (MOFs) is a class of novel crystalline metal-organic hybrid materials, which has received considerable attention in recent decades, on one hand, because of their intriguing structures, and on the other hand, due to their potential applications in chemical probe, gas storage, luminescence, photovoltaic conversion, heterogeneous catalysis, and so on [1-5]. Generally speaking, the desired function of MOFs are mainly determined by their structure. For example, in order to obtain desirable functional materials for gas storage, it is a primary principle that porous MOFs with a stable structure and high surface area should be achieved. Moreover, the precise modification of organic linkers and metal ions can also effectively benefit the enhance the adsorption ability and selectivity of for diverse gas [6,7]. Luminescent MOFs have gradually emerged as effective candidates for fluorescence sensing materials due to their good optical absorption and electron transport properties [8,9]. Recently, some MOFs have been widely employed as luminescent sensors for heavy metal ions and organic pollutant detection, with high sensitivity and selectivity $[10,11]$. Commonly, the MOFs consist of organic ligands and metal ions, that is, the successful construction of MOFs involves an understanding of how organic ligands are designed. Generally, the multiple N/O-donor ligands are the most important candidates in this space as the $\mathrm{N} / \mathrm{O}$ atoms possess a favorable coordinated ability with metal atoms. Therefore, the organic compounds possessing $\mathrm{N}$ or O-donor coordination sites are two types of the important ligands, which synthesize diverse MOFs due to their strong affinities with metal atoms [12-15]. For example, 1,2,4-triazole and its derivatives are effective organic compounds, and serve as $\mathrm{N}$-donor ligands links with metal ions, thereby benefiting the construction for functionalized MOFs [16]. In addition to the $\mathrm{N}$-donor ligands, carboxylic acids are extensively employed desired coordination polymers, due to their varied coordination modes for carboxylic group. However, other important 
factors to the resulting structures of MOFs, including reaction temperature, solvent, coordination geometry of the metal, $\mathrm{pH}$ value, and counteranion, metal-to-ligand ratio [17-20]. Therefore, scientists face challenges in developing controllable synthesis of proposed compounds. It should be mentioned that the different coordination natures of $\mathrm{N}$ - or O-donor ligands can effectively meet the geometric configuration of metal centers. In this context, the mixed N/O-donor ligands strategy can be employed for the construction of desired MOFs. Recently, Chen group have designed the multi-N donor ligand 1-(4- $(1 \mathrm{H}-\mathrm{imidazol}-$ 5-yl)phenyl)-1H-1,2,4-triazole, which potentially have diverse coordination modes due to the favorable multi-N coordination ability with metal atoms. Moreover, considering their good compatibility for the mixed multi-N and carboxylic acid ligands, the group have synthesized a series of various MOFs with good properties [21]. As an extension of this work, we use the N-donor 1-(4-(1H-imidazol-5-yl)phenyl)-1H-1,2,4-triazole (AZN) ligand together with trimesic acid $\left(\mathrm{H}_{3}\right.$ btc $)$ as mixed ligands to construct novel MOFs. We report the structures and property of two MOFs of $\left[\mathrm{Cd}_{2}(\mathrm{AZN})(\mathrm{HAZN})(\mathrm{btc})(\mathrm{Hbtc}) \cdot 4 \mathrm{H}_{2} \mathrm{O}\right] \cdot 2 \mathrm{H}_{2} \mathrm{O}$ (1), and $\left[\mathrm{Zn}_{3}(\mathrm{AZN})_{2}(\mathrm{btc})_{2} \cdot 4 \mathrm{H}_{2} \mathrm{O}\right](2)$ by reactions of different metal salts based on $\mathrm{N} / \mathrm{O}$ donor mixed system of $\mathrm{AZN}$ and $\mathrm{H}_{3}$ btc.

\section{Materials and Methods}

\subsection{Materials and Techniques}

All reagents were obtained from commercial sources, except for AZN ligand, which was obtained according to the literature [22]. Elemental analyses were carried out on an Elementar Vario EL III elemental analyzer. PXRD patterns were recorded on a Bruker D2 Phaser diffractometer with $\mathrm{CuK} \alpha(\lambda=1.5418 \AA)$ radiation. Luminescent tests were carried using HORIBA FluoroMax-4 fluorescence spectrophotometer.

\subsection{Synthesis of $\left[\mathrm{Cd}_{2}(\mathrm{AZN})(\mathrm{HAZN})(\mathrm{btc})(\mathrm{Hbtc}) \cdot 4 \mathrm{H}_{2} \mathrm{O}\right] \cdot 2 \mathrm{H}_{2} \mathrm{O}$ (1)}

The mixed compounds of cadmium nitrate tetrahydrate $(0.05 \mathrm{mmol}, 0.015 \mathrm{~g}), 1-(4-$ (1H-imidazol-5-yl)phenyl)-1H-1,2,4-triazole (AZN, $0.05 \mathrm{mmol}, 0.011 \mathrm{~g}$ ), and Trimesic acid $(0.1 \mathrm{mmol}, 0.016 \mathrm{~g})$ was placed in $25 \mathrm{~mL}$ Teflon-lined stainless steel vessel and stirred in $15 \mathrm{~mL} \mathrm{H} \mathrm{H}_{2} \mathrm{O}$ for $30 \mathrm{~min}$. Then, the mixture reacted at $120{ }^{\circ} \mathrm{C}$ for $48 \mathrm{~h}$. After being cooled, colorless crystals of 1 were obtained (Yield: 72\%). Elemental analysis calcd (\%) for $\mathrm{C}_{40} \mathrm{H}_{38} \mathrm{~N}_{10} \mathrm{O}_{18} \mathrm{Cd}_{2}$ : C 41.01, H 3.27, N 11.96; found: C 40.95, H 3.35, N 12.08. IR (v/ $\left.\mathrm{cm}^{-1}\right)$ : $3448(\mathrm{w}), 3143(\mathrm{~m}), 1720(\mathrm{~m}), 1628$ (s), $1529(\mathrm{~s}), 1488(\mathrm{~m}), 1376(\mathrm{~m}), 1351(\mathrm{~s}), 1268(\mathrm{w})$, $1120(\mathrm{w}), 1072(\mathrm{~m}), 948(\mathrm{w}), 837(\mathrm{~m}), 821(\mathrm{~m}), 790(\mathrm{~m}), 649(\mathrm{~m}), 611(\mathrm{w}), 520(\mathrm{w}), 492(\mathrm{w})$, $421(\mathrm{~m})$.

\subsection{Synthesis of $\left[\mathrm{Zn}_{3}(A Z N)_{2}(b t c)_{2} \cdot 4 \mathrm{H}_{2} \mathrm{O}\right]$ (2)}

MOF 2 was prepared using a similar procedure as MOF 1 by changing the cadmium nitrate tetrahydrate to zinc nitrate hexahydrate $(0.1 \mathrm{mmol}, 0.019 \mathrm{~g})$ (Yield: $65 \%$ ). Elemental analysis calcd (\%) for $\mathrm{C}_{40} \mathrm{H}_{32} \mathrm{~N}_{10} \mathrm{O}_{16} \mathrm{Zn}_{3}$ : C 43.48, $\mathrm{H} 2.92, \mathrm{~N} 12.68$; found: C 43.55, H 3.05, $\mathrm{N}$ 12.72. IR (v/ $\left.\mathrm{cm}^{-1}\right)$ : $3461(\mathrm{~m}), 3389(\mathrm{~m}), 3128(\mathrm{~m}), 2859$ (s), 1641 (s), 1580 (s), 1548 (s), $1488(\mathrm{~s}), 1410(\mathrm{~m}), 1359(\mathrm{~m}), 1271(\mathrm{~m}), 1180(\mathrm{~m}), 1192(\mathrm{w}), 1129(\mathrm{~s}), 1080(\mathrm{~m}), 969(\mathrm{~m}), 838(\mathrm{~m})$, $818(\mathrm{~m}), 786(\mathrm{w}), 679(\mathrm{~m}), 648(\mathrm{w}), 629(\mathrm{~m}), 528(\mathrm{w}), 459(\mathrm{~m})$.

\subsection{Crystallographic Data Collection and Refinements}

The data collection for MOFs 1 and 2 were performed on a Rigaku Saturn 724 CCD diffractometer (Mo K $\alpha$ radiation, $\lambda=0.71073 \AA$ ). All structures were integrated and refined by using the SHELXS-97 [23-25]. The parameters are listed in Table 1. CCDC-2,102,480 and 2,102,481 for MOFs 1 and 2. 
Table 1. Crystallographic data for MOFs 1 and 2.

\begin{tabular}{|c|c|c|}
\hline & 1 & 2 \\
\hline Formula & $\mathrm{C}_{40} \mathrm{H}_{38} \mathrm{~N}_{10} \mathrm{O}_{18} \mathrm{Cd}_{2}$ & $\mathrm{C}_{40} \mathrm{H}_{32} \mathrm{~N}_{10} \mathrm{O}_{16} \mathrm{Zn}_{3}$ \\
\hline Formula weight & 1171.60 & 1104.87 \\
\hline Temperature/K & $296(2)$ & 296(2) \\
\hline Crystal system & Triclinic & Monoclinic \\
\hline Space group & $P-1$ & C $2 / c$ \\
\hline$a / \AA$ & $7.3281(9)$ & $27.035(3)$ \\
\hline$b / \AA$ & $17.205(2)$ & $12.1481(15)$ \\
\hline$c / \AA$ & $18.992(2)$ & $14.9250(18)$ \\
\hline$\alpha /^{\circ}$ & $64.7330(10)$ & 90 \\
\hline$\beta /{ }^{\circ}$ & $88.3760(10)$ & $116.9100(10)$ \\
\hline$\gamma /{ }^{\circ}$ & $80.2420(10)$ & 90 \\
\hline$V\left(\AA^{3}\right)$ & $2131.5(4)$ & $4371.0(9)$ \\
\hline $\mathrm{Z}$, Dcalc $/\left(\mathrm{Mg} / \mathrm{m}^{3}\right)$ & $2,1.826$ & $4,1.679$ \\
\hline$F(000)$ & 1176 & 2240 \\
\hline$\theta$ range ${ }^{\circ}$ & $2.13-27.49$ & $1.69-27.50$ \\
\hline Reflections collected & 17,647 & 14,185 \\
\hline Independent reflections & 9507 & 4924 \\
\hline Goodness-of-fit on $F^{2}$ & 1.003 & 1.029 \\
\hline$R_{1}[I>2 \sigma(I)]^{\mathrm{a}}$ & 0.0248 & 0.0355 \\
\hline$w R_{2}[I>2 \sigma(I)]^{\mathrm{b}}$ & 0.0617 & 0.1006 \\
\hline
\end{tabular}

\section{Results}

\subsection{Structural Descriptions}

3.1.1. Structure of $\left[\mathrm{Cd}_{2}(\mathrm{AZN})(\mathrm{HAZN})(\mathrm{btc})(\mathrm{Hbtc}) \cdot 4 \mathrm{H}_{2} \mathrm{O}\right] \cdot 2 \mathrm{H}_{2} \mathrm{O}(1)$

In this study, MOF 1 crystallized in the triclinic space group $P-1$. Figure 1 shows that the asymmetric unit includes two $\mathrm{Cd}$ (II) atoms, one neutral AZN molecule, one protonated $\mathrm{HAZN}^{+}$, one completely deprotonated $\mathrm{btc}^{3-}$, one partly deprotonated $\mathrm{Hbtc}^{2-}$, four coordinated $\mathrm{H}_{2} \mathrm{O}$ molecules and two lattice $\mathrm{H}_{2} \mathrm{O}$ molecules (Table 1 ). In the asymmetric unit, two distinct $\mathrm{Cd}(\mathrm{II})$ atoms and one protonated $\mathrm{HAZN}^{+}$show a positive five nuclear charge number, while one completely deprotonated $\mathrm{btc}^{3-}$ together with one partly deprotonated $\mathrm{Hbtc}^{2-}$ show five negative charges. In this context, the complex is neutral molecules. The $\mathrm{Cd} 1$ ion is five-coordinated surrounding by one nitrogen atom from AZN molecule, two carboxylic oxygen atoms from one $\mu_{1}-\eta^{1}: \eta^{0}$ carboxyl group of two carboxyl groups and two oxygen atoms from two distinct coordinated $\mathrm{H}_{2} \mathrm{O}$ molecules, forming a distorted trigonal bipyramidal configuration. The $\mathrm{Cd} 2$ atom lies in the distorted octahedral coordination environment with NO5 donor set. Cd2 atom coordinates with O3A atom and O11, O12 atoms of the carboxyl group from one distinct triacid ligand and N6 atom from AZN ligand in the equatorial plane, and two $\mathrm{O}$ atoms from two coordinated water molecules occupies the axial positions with $\mathrm{O} 15-\mathrm{Cd} 2-\mathrm{O} 16$ angle of $172.93(6)^{\circ}$. The $\mathrm{Cd}-\mathrm{O}$ bonds range from 2.2232(14) to 2.5657(15) $\AA$, while the bond angles vary from $52.85(5)$ to $172.93(6)^{\circ}$ (Table S1). In this structure, triacid carboxylate ligands coordinate with Cd(II) atoms to generate one-dimensional (1D) chain structure, while the AZN ligand just as a terminal ligand to coordinated with $\mathrm{Cd}$ (II) metal centers (Figure 2). Interestingly, the molecules of btc $^{3-}$ includes multi-O-donor atoms from the carboxyl groups and AZN ligands possess multi-N atoms, both of which can easily be employed as receptors of hydrogen bond. Therefore, the interaction arising from the hydrogen bonds extend to the adjacent 1D chain into three-dimensional (3D) supramolecular structure (Figure S1). 


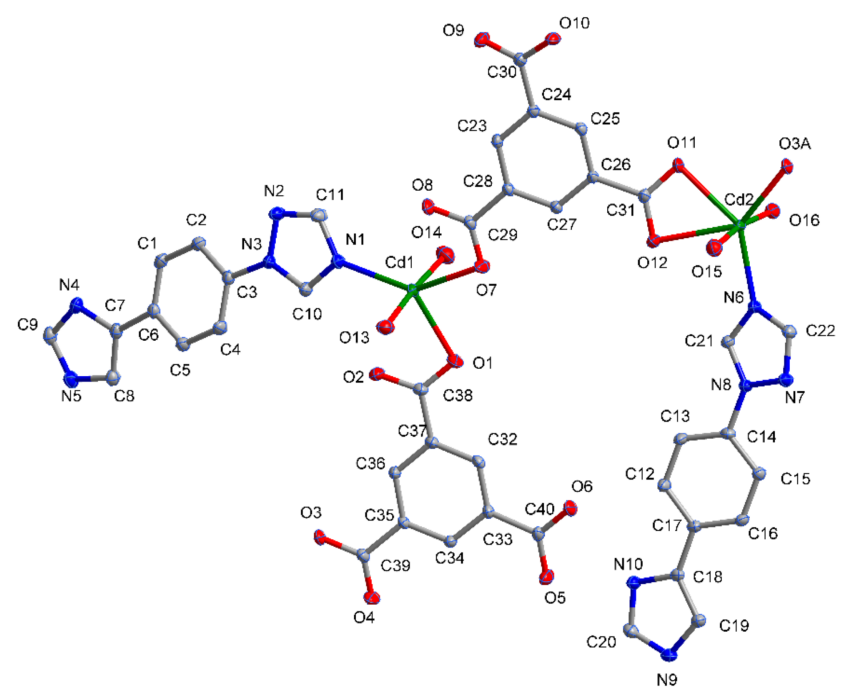

Figure 1. The $\mathrm{Cd}(\mathrm{II})$ atoms coordination environment in $\mathbf{1}$.

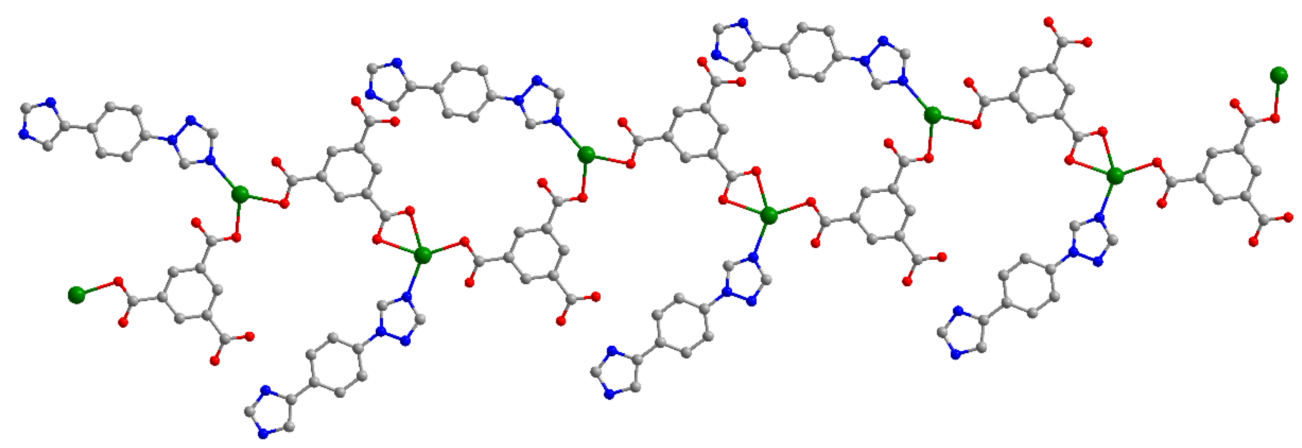

Figure 2. 1D chain structure of 1 .

\subsubsection{Structure of $\left[\mathrm{Zn}_{3}(\mathrm{AZN})_{2}(\mathrm{btc})_{2} \cdot 4 \mathrm{H}_{2} \mathrm{O}\right]$ (2)}

A new MOF 2 was obtained when the different metal salt of $\mathrm{Zn}\left(\mathrm{NO}_{3}\right)_{2} \cdot 6 \mathrm{H}_{2} \mathrm{O}$ replaced the $\mathrm{Cd}\left(\mathrm{NO}_{3}\right)_{2} \cdot 4 \mathrm{H}_{2} \mathrm{O}$ in the reaction of $\mathbf{1}$. X-ray crystallographic analysis showed that MOF $\mathbf{2}$ is monoclinic space group $\mathrm{C} 2 / \mathrm{c}$ (Table 1). From the coordination environment in $\mathbf{2}$, the asymmetric unit has two different $\mathrm{Zn}$ (II) atoms (Figure 3). Zn1 is four-coordinated by two $\mathrm{N}$ atoms (N1 and N1A) from two AZN ligands, and two O atoms (O1 and O1A) from two distinct $\mathrm{btc}^{3-}$ ligands, forming the distorted tetrahedral coordination environment. The Zn1-N and Zn1-O distances are 2.003(2) and 1.9074(19) $\AA$. Zn2 with a $\mathrm{NO}_{5}$ donor set is coordinated by three oxygen atoms $(\mathrm{O} 6, \mathrm{O} 3 \mathrm{C}$ and $\mathrm{O} 4 \mathrm{C})$ from two different $\mathrm{btc}^{3-}$ ligands, two $\mathrm{O}$ atoms (O7 and $\mathrm{O} 8$ ) from two water molecules, and one $\mathrm{N}$ atom (N3B) from AZN to complete a distorted octahedral geometry. The $\mathrm{Zn2}-\mathrm{O}$ distances are in range of 1.9940(17)2.198(3) $\AA$ and the Zn2-N distances is 2.057(2) $\AA$, respectively, while coordinated bond angles around $\mathrm{Zn} 2$ range from 60.56(8) to $174.31(9)^{\circ}$ (Table S1). In MOF 2, the $\mathrm{H}_{3}$ btc ligands are completely deprotonated to be $\mathrm{btc}^{3-}$, and act as 3-connected nodes to coordinate with three $\mathrm{Zn}(\mathrm{II})$ ions through its each carboxylate group in a $\mu_{1}-\eta^{1}: \eta^{0}$-monodentate or $\mu_{1}-\eta^{1}: \eta^{1}$ chelating coordination modes, producing a 1D chain (Figure 4). As a return, the Zn(II) ions are linked by AZN and btc $^{3-}$, which give rise to the complicated 3D framework, where 1D square channels with a pore diameter approximately $5.8 \AA$ A exist in the single 3D framework (Figure 5). Topological method can be used to analysis the framework. Each btc ${ }^{3-}$ ligand links three $\mathrm{Zn}$ (II) atoms, and $\mathrm{Zn} 1$ atom links two $\mathrm{btc}^{3-}$ ligands and two $\mathrm{Zn}$ (II) atoms by two linear AZN ligands, while each Zn2 connects two btc ${ }^{3-}$ ligands and one $\mathrm{Zn}(\mathrm{II})$ atom by one linear AZN ligand. In this context, the $\mathrm{Zn} 1, \mathrm{Zn} 2, \mathrm{btc}^{3-}$, and AZN are considered as 4-, 3-, 3-, and 2-connected nodes, respectively, therefore, the resulting framework can be simplified as a trinodal $(3,4)$-connected nor-3,4-C2/m net with its Point (Schläfli) symbol of $\left(6 \cdot 8^{2}\right)_{4}\left(6^{2} \cdot 8^{2} \cdot 10^{2}\right)$ (Figure 6) [26]. As the single 3D framework has 1D square channels with 
a pore diameter approximately $5.8 \AA$, it allows other two similar framework to interpenetrate in the channels, and as a result, the 3D networks of 2 interlock each other, forming a 3-fold interpenetration networks (Figure 7). It should be mentioned that both of the MOF 2 and the reported structure of $\left[\mathrm{Co}_{3}(\mathrm{~L})_{2}(\mathrm{BTC})_{2}\left(\mathrm{H}_{2} \mathrm{O}\right)_{4}\right] \cdot \mathrm{H}_{2} \mathrm{O}$ crystallize in the same monoclinic $\mathrm{C} 2 / \mathrm{c}$ space group with similar cell parameters (Table 1 ), they are isomorphous and isostructural as confirmed by $\mathrm{X}$-ray crystallographic analysis [21]. The reported compound of $\left[\mathrm{Co}_{3}(\mathrm{~L})_{2}(\mathrm{BTC})_{2}\left(\mathrm{H}_{2} \mathrm{O}\right)_{4}\right] \cdot \mathrm{H}_{2} \mathrm{O}$ has the same composition constructed by the mixed N/O-donor ligands, but with different metal centers. However, the different $\mathrm{Zn}$ (II)/Co(II) metal centers have the same coordination configuration, and both of them act as 3, 4-nodes, which are further extended by the mixed ligands to form $(3,4)$-connected nor-3,4-C2/m net with its Point (Schläfli) symbol of $\left(6 \cdot 8^{2}\right)_{4}\left(6^{2} \cdot 8^{2} \cdot 10^{2}\right)$. But for the compound 1 built from the same N/O mixed ligands in this study, the metal Cd(II) centers show different coordination configurations, which result in different structures. Certainly, the different composition can affect the resulting structures. The reported MOF of $\left[\mathrm{Co}_{3}(\mathrm{~L})_{2}(\mathrm{OBTC})_{2}\left(\mathrm{H}_{2} \mathrm{O}\right)_{2}\right]$ built from AZN and the isomer $\mathrm{H}_{3} \mathrm{OBTC}$ of $\mathrm{H}_{3}$ btc [21], the quite different coordination modes of $\mathrm{OBTC}^{3-}$ make distinct structures for these two Co-based compounds.

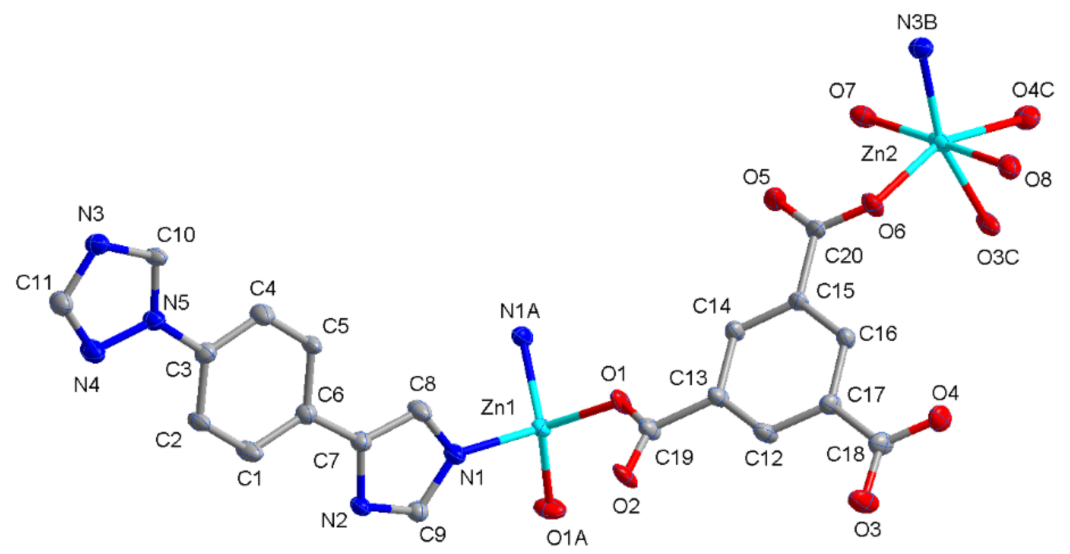

Figure 3. The $\mathrm{Zn}(\mathrm{II})$ atom coordination environment in $\mathbf{2}$.

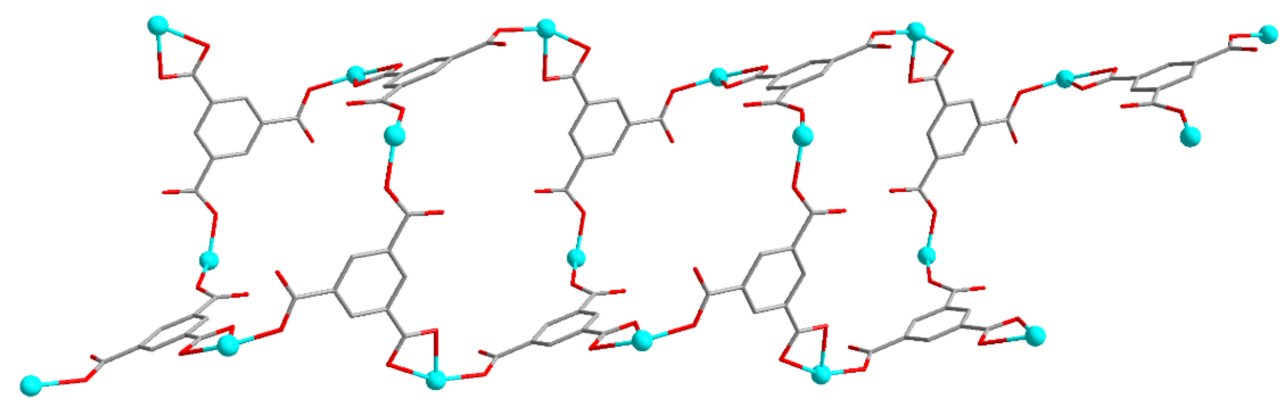

Figure 4. 1D chain structure built from the Zn-carboxylate chain in 2. 


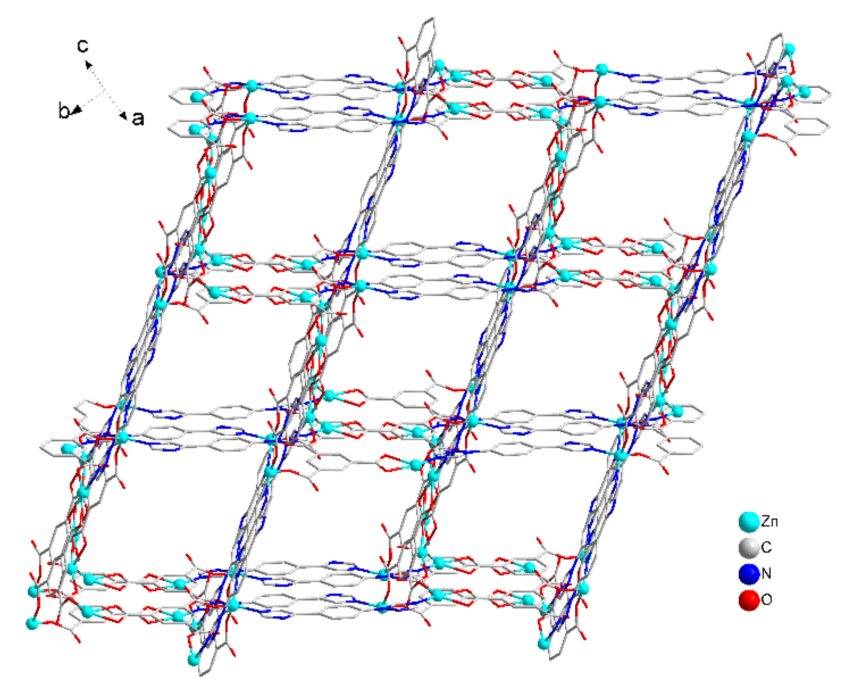

Figure 5. 3D structure with 1D void channels.

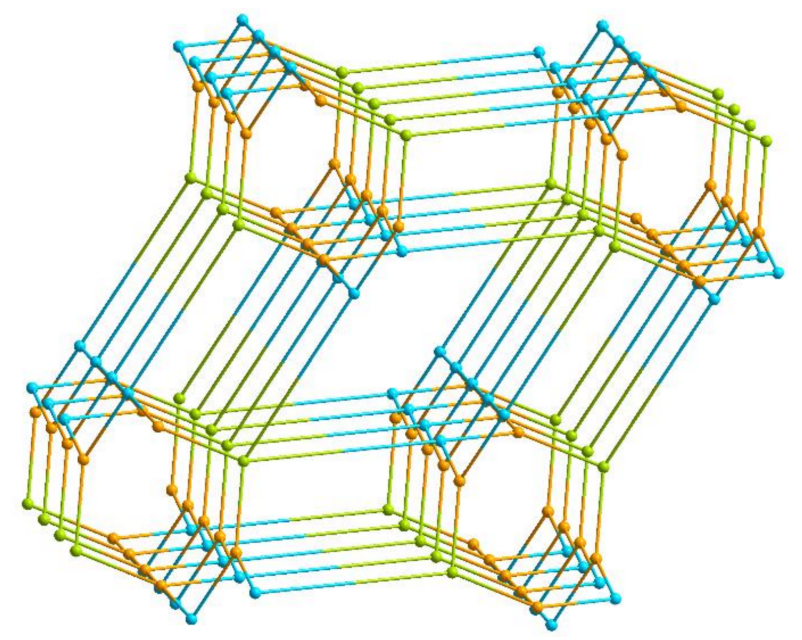

Figure 6. Three-dimensional topological structure with its Point (Schläfli) symbol of $\left(6 \cdot 8^{2}\right)_{4}\left(6^{2} \cdot 8^{2} \cdot 10^{2}\right)$.

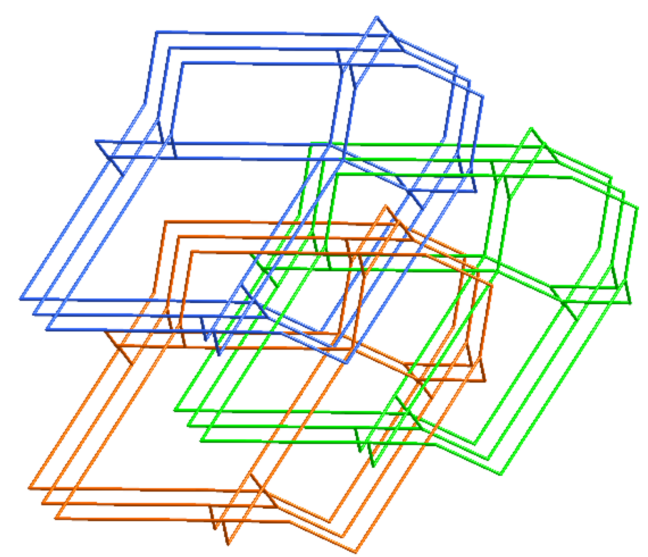

Figure 7. Three-fold interpenetrating net of 2.

\subsection{Thermal Analyses and X-ray Powder Diffraction Analyses}

The thermal stabilities of MOFs 1 and 2 were evaluated by thermal gravimetric analyses (Figure S2). The compound $\mathbf{1}$ indicates a weight loss of $6.60 \%$, ranging from 80 to $120{ }^{\circ} \mathrm{C}$, based on the loss of the coordinated and lattice $\mathrm{H}_{2} \mathrm{O}$ molecules (calc. 6.52\%) and the framework collapse at approximately $320^{\circ} \mathrm{C}$. A loss of $9.48 \%$ (calc. $9.22 \%$ ) was found for 2 , ranging from 120 to $190^{\circ} \mathrm{C}$, and followed by the continual collapse at $350{ }^{\circ} \mathrm{C}$. The 
pure phases for MOFs $\mathbf{1}$ and $\mathbf{2}$ were confirmed, as their patterns from the powder XRD fit within the simulated pattern (Figures S3 and S4).

\subsection{Photoluminescent Property}

Metal-organic frameworks built from $\mathrm{d}^{10}$, such as $\mathrm{Zn}(\mathrm{II})$ and $\mathrm{Cd}(\mathrm{II})$ metal centers and aromatic organic molecules with $\pi$-conjugated system may have potential photoluminescent properties [27-29]. In this regard, we carried out the study on their fluorescence properties of MOFs 1 and 2, together with AZN ligand (Figure 8). As shown in Figure 8, MOFs 1 shows an emission maxima at $392 \mathrm{~nm}$ upon excitation at $342 \mathrm{~nm}$, while MOF 2 exhibits emission maxima at $430 \mathrm{~nm}$ upon excitation at $350 \mathrm{~nm}$. MOFs 1 and 2 show $18 \mathrm{~nm}$ blue-shift and $20 \mathrm{~nm}$ red-shift in comparison with the emission peak at $410 \mathrm{~nm}$ from AZN ligand. The emission nature of MOFs 1 and $\mathbf{2}$ may originate in intraligand charge transfer [30]. Under the same condition, MOF 2 has a stronger fluorescent emission in contrast with MOF 1. Enhanced luminescence of the MOF 1 compared with 2, under the same conditions, may enhance its conformational rigidity and decrease the nonradiative energy loss due to the coordination interactions between the metal $\mathrm{Zn}$ (II) atom and the ligand.

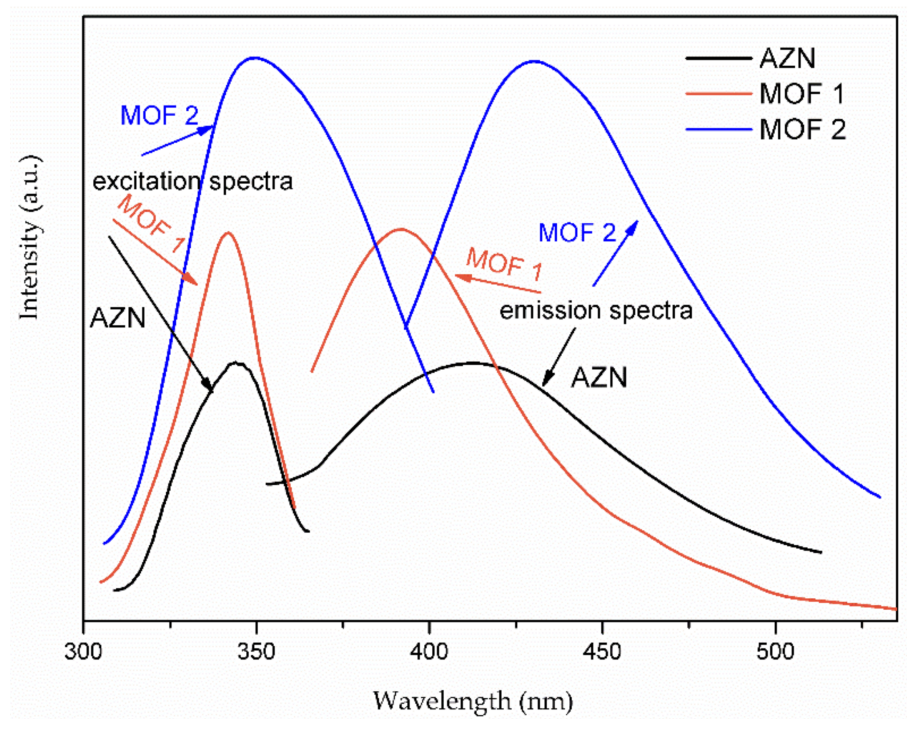

Figure 8. Luminescent excitation and emission spectra of AZN and MOFs 1-2.

Furthermore, the quantum yield (QY) and decay lifetimes are areas that need to be investigated further (Figure 9). The exponential function as $I(t)=A \exp (-t / \tau)$ can be used to determine the luminescence lifetimes and the results are 36.23, and $62.54 \mathrm{~ns}$ for 1 and 2 [31]. Apparently, the luminescence lifetime of $\mathbf{2}$ is much longer than MOF $\mathbf{1}$, however, both MOFs 1 and 2 have shorter luminescence lifetimes, which are attributable to the characteristic of a singlet state, rather than a triplet state $\left(>10^{-3} \mathrm{~s}\right)$ [32]. Moreover, the corresponding QY values of MOFs $\mathbf{1}$ and 2 are $4.35 \%$, and $5.68 \%$. 
(a)

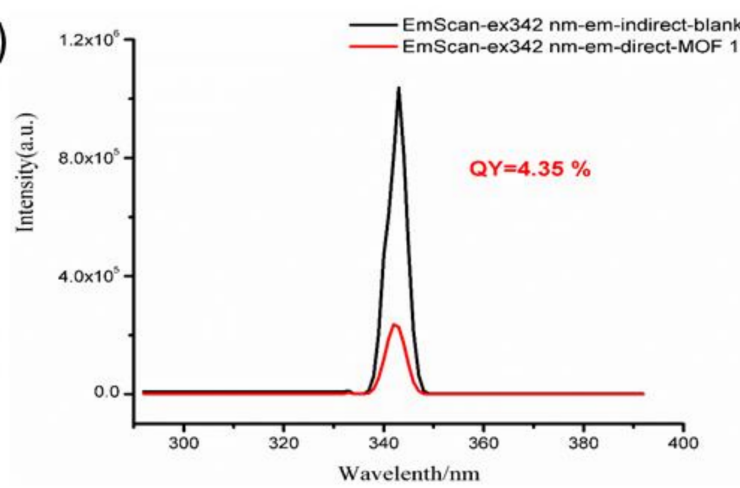

(a)

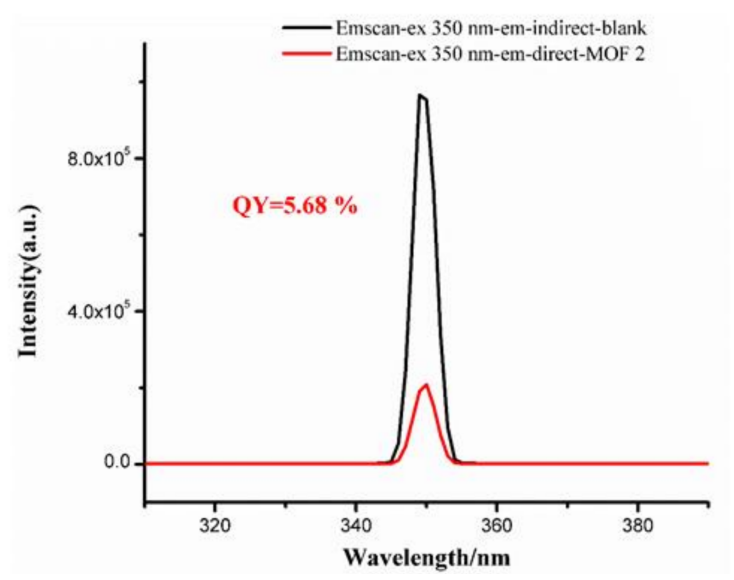

(b)

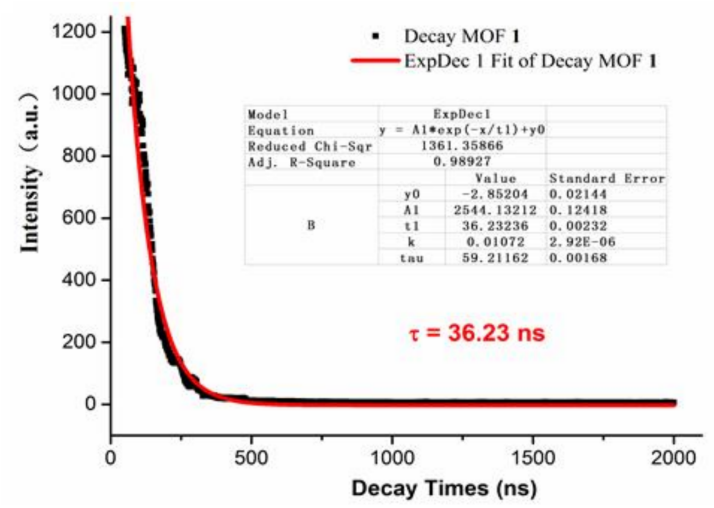

(b)

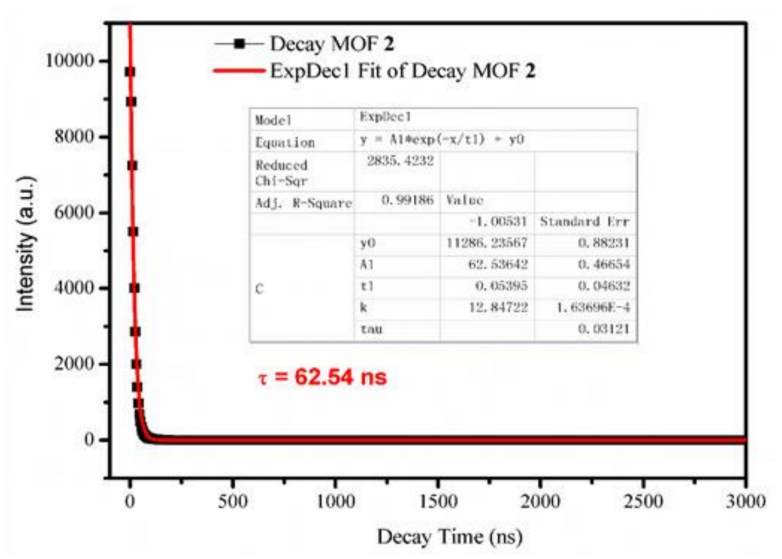

Figure 9. The quantum yield; and (a) decay curves; (b) for MOF 1 and MOF 2.

\section{Conclusions}

Two new metal-organic MOFs based on $\mathrm{N}$-donor AZN and O-donor $\mathrm{H}_{3}$ btc mixed ligands have been obtained by reactions with different metal salts under hydrothermal reaction. MOF 1 is a $1 \mathrm{D}$ chain structure, while $\mathbf{2}$ is a 3D networks with a three-fold interpenetration topology with its Point (Schläfli) symbol of $\left(6 \cdot 8^{2}\right)_{4}\left(6^{2} \cdot 8^{2} \cdot 10^{2}\right)$. The study has further demonstrated that the on N/O-donor mixed ligands can effectively be employed to construct metal-organic coordination polymers. Apparently, many factors have a significant effect on the resulting structures, including the nature of different metal centers and ligands. Moreover, the luminescent properties of MOFs $\mathbf{1}$ and $\mathbf{2}$ have been studied.

Supplementary Materials: The following are available online at https:/ / www.mdpi.com/article/10 .3390 / cryst11091129/s1, Figure S1. The 3D supramolecular structure of $\mathbf{1}$. Figure S2. TG curves of MOFs 1 and 2. Figure S3. PXRD of MOF 1: a, simulated; b, experimental. Figure S4. PXRD of MOF 2: a, simulated; b, experimental. Table S1. Bond lengths [A] and bond angles [ $\left.{ }^{\circ}\right]$ for MOFs 1 and 2.

Author Contributions: Z.L. charged the project, carried out the experiments and organized this paper. Y.L., Y.R., S.Y., C.H., M.Z., R.J. performed the experiments. Y.L. and H.Y. dealt with the data. All authors have read and agreed to the published version of the manuscript.

Funding: This research was funded by National Natural Science Foundation of China, grant number U1304206 \& No.21801112; Natural Science Foundation of Henan Province, grant number: 212300410374; Science and Technology Project of Hennan Province, grant number: 212102210549, and the Key Scientific Research Project of Higher Education of Henan Province, grant number: 18A150012 \& 13A150799. The APC was funded by National Natural Science Foundation of China, grant number 21801112.

Institutional Review Board Statement: Not applicable.

Informed Consent Statement: Not applicable. 
Acknowledgments: We are grateful to National Natural Science Foundation of China (No. U1304206, No. 21801112), Natural Science Foundation of Henan Province (No. 212300410374), Science and Technology Project of Hennan Province (No. 212102210549), and the Key Scientific Research Project of Higher Education of Henan Province (No. 18A150012, 13A150799).

Conflicts of Interest: The authors declare no conflict of interest.

\section{References}

1. Du, M.; Li, C.P.; Liu, C.S.; Fang, S.M. Design and construction of coordination polymers with mixed-ligand synthetic strategy. Coord. Chem. Rev. 2013, 257, 1282-1305. [CrossRef]

2. Furukawa, H.; Cordova, K.E.; O'Keeffe, M.; Yaghi, O.M. The chemistry and applications of metal-organic frameworks. Science 2013, 341, 974. [CrossRef] [PubMed]

3. Carter, K.P.; Thomas, K.E.; Pope, S.J.A.; Holmberg, R.J.; Butcher, R.; Murugesu, M.; Cahill, C.L. Supramolecular assembly of molecular rare-earth-3,5-dichlorobenzoic acid-2, $2^{\prime}: 6^{\prime}, 2^{\prime \prime}$-terpyridine materials: Structural systematics, luminescence properties, and magnetic behavior. Inorg. Chem. 2016, 55, 6902-6915. [CrossRef]

4. Zhai, Q.G.; Bu, X.; Mao, C.; Zhao, X.; Feng, P. Systematic and dramatic tuning on gas sorption performance in heterometallic metal-organic frameworks. J. Am. Chem. Soc. 2016, 138, 2524-2527. [CrossRef] [PubMed]

5. Kang, Y.S.; Lu, Y.; Chen, K.; Zhao, Y.; Wang, P.; Sun, W.Y. Metal-organic frameworks with catalytic centers: From synthesis to catalytic application. Coord. Chem. Rev. 2019, 378, 262-280. [CrossRef]

6. Zhao, D.; Cui, Y.; Yang, Y.; Qian, G. Sensing-functional luminescent metal-organic frameworks. CrystEngComm 2016, 18, 3746-3759. [CrossRef]

7. Chen, S.S. The roles of imidazole ligands in coordination supramolecular systems. CrystEngComm 2016, 18, 6543-6565. [CrossRef]

8. Lu, Z.; Li, Y.; Hao, C.; Ru, Y.; Yang, S.; Zhang, N.; Fu, Y.; Wu, W.; Zhou, Y. Synthesis, Crystal Structure and Luminescent/magnetic Properties of Two Metal-organic Frameworks Based on Multi-N/O-donor Mixed Ligands. Chinese J. Struc. Chem. 2021, 40, 1122-1130.

9. Chen, S.S.; Zhang, Z.Y.; Liao, R.B.; Zhao, Y.; Wang, C.; Qiao, R.; Liu, Z.D. A photoluminescent Cd(II) coordination polymer with potential active sites exhibiting multiresponsive fluorescence sensing for trace amounts of $\mathrm{NACs}_{\text {and }} \mathrm{Fe}^{3+}$ and $\mathrm{Al}^{3+}$ ions. Inorg. Chem. 2021, 60, 4945-4956.

10. Wang, C.X.; Xia, Y.P.; Yao, Z.Q.; Xu, J.; Chang, Z.; Bu, X.H. Two luminescent coordination polymers as highly selective and sensitive chemosensors for CrVI-anions in aqueous medium. Dalton Trans. 2019, 48, 387-394. [CrossRef]

11. Zhao, D.; Zhang, J.; Yue, D.; Lian, X.; Cui, Y.; Yang, Y.; Qian, G. A highly sensitive near-infrared luminescent metal-organic framework thermometer in the physiological range. Chem. Commun. 2016, 52, 8259-8262. [CrossRef]

12. Wang, T.; Chen, H.; Zhang, R.; Liu, J. The research of down conversion materials based on metal-complexes for solar cells, Chinese J. Inorg. Chem. 2018, 34, 1007-1017.

13. Cui, Y.; Li, B.; He, H.; Zhou, W.; Chen, B.; Qian, G. Metal-organic frameworks as platforms for functional materials. Acc. Chem. Res. 2016, 49, 483-493. [CrossRef] [PubMed]

14. Chen, S.S.; Liu, Q.; Zhao, Y.; Qiao, R.; Sheng, L.Q.; Liu, Z.D.; Yang, S.; Song, C.F. New metal-organic frameworks constructed from the 4-imidazole-carboxylate ligand: Structural diversities, luminescence, and gas adsorption properties. Cryst. Growth Des. 2014, 14, 3727-3741. [CrossRef]

15. Biswas, S.; Vanpoucke, D.E.P.; Verstraelen, T.; Vandichel, M.; Couck, S.; Leus, K.; Liu, Y.-Y.; Waroquier, M.; Speybroeck, V.V.; Denayer, J.F.M.; et al. New functionalized metal-organic frameworks MIL-47-X (X $\left.=-\mathrm{Cl},-\mathrm{Br},-\mathrm{CH}_{3},-\mathrm{CF}_{3},-\mathrm{OH}_{1}-\mathrm{OCH}_{3}\right)$ : Synthesis, characterization, and $\mathrm{CO}_{2}$ adsorption properties. J. Phys. Chem. C 2013, 117, 22784-22796. [CrossRef]

16. Ouellette, W.; Jones, S.; Zubieta, J. Solid state coordination chemistry of metal-1,2,4-triazolates and the related metal-4pyridyltetrazolates. CrystEngComm 2011, 13, 4457-4485. [CrossRef]

17. Zhu, M.A.; Guo, X.Z.; Xiao, L.; Chen, S.S. A new Cd(II) coordination compound based on 4-(1,2,4-Triazol-4-yl)phenylacetic acid: Synthesis, structure and photoluminescence property. Chin. J. Struct. Chem. 2018, 37, 437-444.

18. Chen, S.S.; Li, J.L.; Li, W.D.; Guo, X.Z.; Zhao, Y. Four new transition metal coordination polymers based on mixed 4-imidazole and carboxylate-sulfonate ligands: Syntheses, structures, and properties. J. Solid State Chem. 2019, 277, 510-518. [CrossRef]

19. Mondal, S.S.; Dey, S.; Baburin, I.A.; Kelling, A.; Schilde, U.; Seifert, G.; Janiak, C.; Holdt, H.-J. Syntheses of two imidazolate-4amide-5-imidate linker-based hexagonal metal-organic frameworks with flexible ethoxy substituent. CrystEngComm 2013, 15, 9394-9399. [CrossRef]

20. Zang, S.Q.; Dong, M.M.; Fan, Y.J.; Hou, H.W.; Mak, T.C.W. Four cobaltic coordination polymers based on 5-iodo-isophthalic acid: Halogen-related interaction and solvent effect. Cryst. Growth Des. 2012, 12, 1239-1246. [CrossRef]

21. Chen, S.S.; Han, S.S.; Ma, C.B.; Li, W.D.; Zhao, Y. A series of metal-organic frameworks: Syntheses, structures and luminescent detection, gas adsorption, magnetic properties, Cryst. Growth Des. 2021, 21, 869-885. [CrossRef]

22. Li, W.D.; Chen, S.S.; Han, S.S.; Zhao, Y. The syntheses, structures, and properties of metal-organic frameworks based on mixed multi-N donor and carboxylate ligands. J. Solid State Chem. 2020, 283, 121133. [CrossRef]

23. SAINT, Version 6.2; Bruker AXS, Inc.: Madison, WI, USA, 2001.

24. Sheldrick, G.M. SADABS, University of Göttingen: Göttingen, Germany, 1997.

25. Sheldrick, G.M. SHELXTL, Version 6.10; Bruker Analytical Xray Systems: Madison, WI, USA, 2001. 
26. Chen, S.S.; Fan, J.; Okamura, T.A.; Chen, M.S.; Su, Z.; Sun, W.Y.; Ueyama, N. Synthesis, crystal structure, and photoluminescence of a series of Zinc(II) coordination polymers with 1,4-Di(1H-imidazol-4-yl)benzene and varied carboxylate ligands. Cryst. Growth Des. 2010, 10, 812-822. [CrossRef]

27. Hu, Z.Y.; Zhao, M.; Su, J.; Xu, S.; Hu, L.; Liu, H.; Zhang, Q.; Zhang, J.; Wu, J.; Tian, Y. Three coordination polymers based on a star-like geometry $4,4^{\prime}, 4^{\prime \prime}$-nitrilotribenzoic acid ligand and their framework dependent luminescent properties. J. Solid State Chem. 2018, 258, 328-334. [CrossRef]

28. Sun, Y.X.; Sun, W.Y. Zinc(II)- and cadmium(II)-organic frameworks with 1-imidazole-containing and 1-imidazole-carboxylate ligands. CrystEngComm 2015, 17, 4045-4063. [CrossRef]

29. Chen, S.S.; Sheng, L.Q.; Zhao, Y.; Liu, Z.D.; Qiao, R.; Yang, S. Syntheses, structures, and properties of a series of polyazaheteroaomatic core-based $\mathrm{Zn}(\mathrm{II})$ coordination polymers together with carboxylate auxiliary ligands. Cryst. Growth Des. 2016, 16, $229-241$. [CrossRef]

30. Li, X.J.; Jiang, F.L.; Wu, M.Y.; Chen, L.; Qian, J.J.; Zhou, K.; Yuan, D.Q.; Hong, M.C. Construction of two microporous metal-organic frameworks with Flu and Pyr topologies based on $\mathrm{Zn}_{4}\left(\mu_{3}-\mathrm{OH}\right)_{2}\left(\mathrm{CO}_{2}\right)_{6}$ and $\mathrm{Zn}_{6}\left(\mu_{6}-\mathrm{O}\right)\left(\mathrm{CO}_{2}\right)_{6}$ secondary building units. Inorg. Chem. 2014, 53, 1032-1038. [CrossRef]

31. Choi, J.H.; Choi, Y.J.; Lee, J.W.; Shin, W.H.; Kang, J.K. Tunability of electronic band gaps from semiconducting to metallic states via tailoring Zn ions in MOFs with Co ions. Phys. Chem. Chem. Phys. 2009, 11, 628-631. [CrossRef] [PubMed]

32. Zhang, M.; Feng, G.; Song, Z.; Zhou, Y.P.; Chao, H.Y.; Yuan, D.; Tan, T.T.; Guo, Z.; Hu, Z.; Tang, B.Z.; et al. Two-dimensional metal-organic framework with wide channels and responsive turn-on fluorescence for the chemical sensing of volatile organic compounds. J. Am. Chem. Soc. 2014, 136, 7241-7244. [CrossRef] 